\title{
Driving forces of landscape change - current and new directions
}

\author{
Matthias Bürgi*, Anna M. Hersperger and Nina Schneeberger \\ Swiss Federal Institute of Forest, Snow and Landscape Research (WSL), CH-8903 Birmensdorf, Switzerland; \\ *Author for correspondence (e-mail: matthias.buergi@wsl.ch)
}

Received 8 April 2003; Accepted in revised form 5 March 2004

Key words: Land-use planning, Land-use and land-cover change, Landscape history, Persistence, Precursors of change, Standard procedure

\begin{abstract}
The concept of driving forces is gaining increasing attention in landscape-change research. We summarize the state of the art of this field and present new conceptual and methodological directions for the study of driving forces of landscape changes. These new directions address four major challenges faced by landscape-change studies, i.e., studying processes and not merely spatial patterns, extrapolating results in space and time, linking data of different qualities, and considering culture as a driver of landscape change. The proposed research directions include: studying landscape change across borders and transects, focusing on persistence as well as change, investigating rates of change, considering attractors of landscape change, targeting correlation and causality, and searching for precursors of landscape change. Based on established knowledge and the new approaches we outline a standard procedure to study driving forces of landscape change. We anticipate that our analytical and systematic approach increases the relevance of studies of landscape change for science as well as for the solution of real world problems.
\end{abstract}

\section{Introduction}

Landscape is the prime sphere, where the combined effects of society and nature become visible. As societies and nature are dynamic, change is an inherent characteristic of landscapes. Indeed, Forman and Godron (1986) offered a scientific framework of landscape ecology based on the three qualities structure (spatial relationship), function (flow), and change (dynamics). Interest in models of landscape change started early (Baker 1989) and such models became widespread with the recognition that land-use change is one of the major factors affecting global environmental change (Dale et al. 1993; McDonnell and Pickett 1993; Meyer and Turner 1994).

Landscape change has primarily been studied in cases where it leads to severe environmental problems. There is for example a long tradition of interdisciplinary work about the causes of land degrada- tion and soil erosion (Blaikie 1985; Blaikie and Brookfield 1987; Adams 1990). Today, the study of causes, processes, and consequences of land-use and land-cover change is one of the main research topics of landscape ecology (Wu and Hobbs 2002), and is also relevant for ecology (Dale et al. 2000). As today's landscapes are the result of many layers of past natural processes and human interventions, a historical perspective is needed (Russell 1997). Such a landscape history provides valuable information for managing cultural landscapes (Blaikie and Brookfield 1987; Cronon 2000; Russell 1994; Tress et al. 2001), for land-use planning (Berger 1987; Hersperger 1994; Marcucci 2000), and for restoration ecology (Egan and Howell 2001).

We identify four serious challenges to landscapechange studies:

(a) studying processes and not merely spatial patterns: Landscape-change studies have so far mainly 
focussed on the documentation and analysis of spatial patterns and have paid considerably less attention to landscape function and therewith processes. This bias is common to the entire field of landscape ecology (Wiens 1995; Hobbs 1997). Understanding landscape changes, however, requires a sound understanding of the underlying processes. A historical approach bears the potential to analyse processes, since processes clearly have a temporal component. But convincing examples of integrative studies of processes of landscape change are still missing.

(b) extrapolating results in time and space: The results of landscape studies are always specific in contexts, actors, main processes, scale, and resolution. As every landscape is unique, it is problematic to transfer results gained in one landscape to another, and it is similarly difficult to extrapolate results in time (Veldkam and Lambin 2001). Although some insights about landscape change are of more general character, such as the importance of topography on settlement patterns, the prerequisites for their extrapolation to other landscapes are often unclear.

(c) linking data of different qualities: Studies of landscape change often face problems handling data of different qualities, especially if they combine data from social sciences with data from natural sciences. Three main issues can be discerned: First, most social science studies are conducted at other scales than natural science studies (Vogt et al. 2002). Second, whereas natural sciences often collect geo-referenced data, difficulties may arise if we try to relate social science data to a specific geographic place. Third, natural scientists usually give more credibility to quantitative data than to qualitative data, which makes it difficult for the social and natural scientists to interact and to integrate their studies (Bürgi and Russell 2001; Vogt et al. 2002). Historical records, which are especially relevant for landscape-change studies, often simply do not meet the rigorous ecologist's demand for quantification (Whitney 1994).

(d) considering culture as a driver of landscape change: The influence of culture on landscape change has recently gained increased attention (Rockwell 1994; Nassauer 1995, 1997; Naveh 2001). When comparing changing landscapes across continents, the influence of culture seems obvious. However, convincing approaches to integrate the cultural dimension into studies of landscape change are missing. Culture is one of the most complex dimensions of environmental change and usually remains a vague concept. There is even serious disagreement whether culture is a narrow concept focusing on attitudes, beliefs, norms, and knowledge (Rockwell 1994) or if culture encompasses aspects such as population development, economy, technology, and political processes. In the later case, it is impossible to assign culture an independent direct effect on the environment (Proctor 1998).

We propose the study of driving forces as a very promising approach to address these four challenges to landscape-change studies. In this paper we (a) discuss the state of the art of the concept of driving forces, (b) present new directions for the study of driving forces which address the above discussed challenges to landscape-change studies, and (c) propose a standard procedure to study driving forces of landscape change. Even though we focus on landscape changes, many aspects can easily be applied to the study of changes in smaller or larger areas.

\section{The concept of 'driving forces' - state of the art}

\section{Definitions}

Driving forces are the forces that cause observed landscape changes, i.e., they are influential processes in the evolutionary trajectory of the landscape. These forces have also been called keystone processes (Marcucci 2000) or drivers (Wood and Handley 2001). The study of driving forces of landscape change has a long tradition in geography and landscape research (Wood and Handley 2001). For example, Wirth (1969) asked for a 'general culturalgeographic theory of forces' and distinguished between economic forces, social forces, and public forces. More than 10 years ago, Kates, Turner and Clark (1990) concluded from the papers collected in the volume 'The earth as transformed by human action' (Turner et al. 1990) that a general theory of human-environment relationships would have to conceptualize the relations among (1) the driving forces of human-induced change, (2) the processes and activities among them, and (3) human behaviour and organization. The driving forces form a complex system of dependencies, interactions, and feedback loops and they affect several temporal and spatial levels. It is therefore difficult to analyze and represent them adequately (e.g., Blaikie 1985).

Landscape-change studies document and interpret the change of the landscape over time. A distinction can be made between studies interpreting human im- 
pacts as one of many influences and studies specifically focussing on the interrelationship between humans and nature. Treating human impacts like natural disturbances or site factors might be appropriate for analysing a single habitat (e.g., Christensen 1989; Magnuson 1990). However, understanding landscapes and regions often require the study of the connections between people and their environment. Such an integrative perspective is also needed if one is interested in changing societal demands due to an altered natural environment.

\section{Types of driving forces}

Five major types of driving forces can be identified: socioeconomic, political, technological, natural, and cultural driving forces (Brandt, Primdahl and Reenberg 1999). The socioeconomic driving forces are primarily rooted in the economy. Today, the market economy, globalisation, and the effects of WTO (World Trade Organization) Agreements are especially strong drivers. Since socioeconomic needs are expressed in political programs, laws and policy, the socioeconomic and political driving forces are strongly interlinked. But also technology has shaped the landscape enormously. Striking examples are the distinct impacts of railroads and highways on settlement patterns. In the near future, information technology is likely to become an important driving force of landscape change (Kienast, Bürgi and Wildi in press). For the natural driving forces we distinguish between site factors, such as climate, topography, and soil characteristics, and natural disturbances. Natural disturbances can be slow- or fast-acting and site factors are short-range stable but long-term variable. Today, the major slow-acting natural disturbance is global change. Fast-acting natural disturbances, such as avalanches, mudslides, and hurricanes, can profoundly affect landscapes and regions. Culture unquestionably leaves a deep imprint on landscapes as culture structures landscapes, while in turn landscapes inoculate culture (Nassauer 1995). For example, the landscape of any American's home is immediately interpreted for what it says about the owner. In turn, people make landscapes according to what they believe their neighbours will think (Nassauer 1995). However, as argued above, culture is one of the most complex dimensions of environmental change and usually remains a vague concept.

\section{Characteristics of driving forces}

What is identified as a driving force of landscape change is determined by the spatial, temporal, and institutional scale of the system under study. It is important to find a sound balance between generalization and specification. Very general statements, such as 'Peoples' responses to economic opportunities, as mediated by institutional factors, drive land-cover changes' (Lambin et al. 2001) or 'The main force behind change is the reorganisation of the existing structures to optimise their functioning' (Antrop 1998), greatly reduce the complexity of the system under study. Some simplification is necessary as it is impossible to comprehend all aspects influencing landscape changes. Thus, every study requires an appropriate scale of investigation. Usually, the relevant levels are on the time axis months, years, and decades, on the institutional axis groups of actors, communities, and states, and on the spatial axis they extend from units of production to states (Figure 1). This does not mean, however, that the other levels can be ignored.

There are always factors behind the ones directly causing a certain change. It is therefore often appropriate to distinguish between primary, secondary, and tertiary driving forces, as driving forces characteristically have to be interpreted in nested scales of explanations (sensu Blaikie and Brookfield 1987). In some cases, we can limit our analysis to the effect of a single driving force, such as a specific policy subject and its effect on landscapes over time (e.g., Baur 2002; Bürgi and Schuler 2003).

To explain changes in a specific landscape, the distinction between intrinsic and extrinsic driving forces is helpful. For example, if the system includes an entire municipality, the community-level regulations are intrinsic driving forces, whereas legislation and regulation on the state and international level are extrinsic driving forces, i.e., they are part of the context.

Landscape change is not always a result of planned and intentional actions. It also can 'happen' as an unexpected side effect. Thus, it is advisable to distinguish between intentional and accidental landscape changes and their respective driving forces.

\section{Methods to study driving forces}

The study of driving forces is problem oriented and in practice not restricted to a specific method or framework. However, the methodological approach 


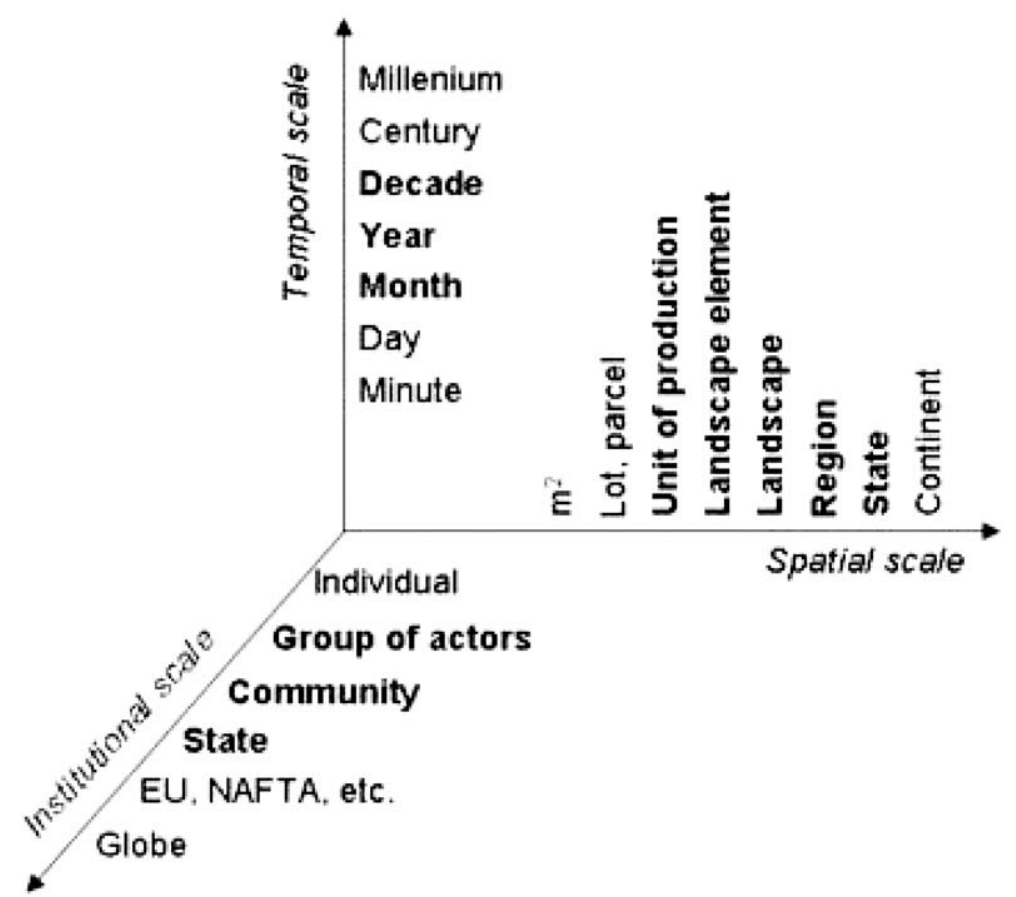

Figure 1. Spatial, temporal and organizational scale of the system under study. In bold, the most important scalar levels are highlighted.

of most studies roots in general systems theory. Clearly, defining the system under study, its boundaries, and components is essential. The systems approach allows us to describe the state of the landscape, the processes within the landscape, and the reactions of the landscape over time (Leser 1991; Naveh and Liebermann 1994). According to hierarchy theory (Allen and Starr 1982; Urban, O’Neill and Shugart 1987), landscape systems can be decomposed into functional components, which can then be studied. Since landscapes are enormously complex systems, the system (especially the extent and the level of hierarchy) is best described in the light of the question. Often, a graphic depiction of the relevant landscape aspects and elements, main group of actors, and most important socio-economical, political, technological, natural, and cultural driving forces is sufficient to start the analysis. For example, Brandt, Primdahl and Reenberg (1999) use a simple framework focusing on farm size, farm type, and driving forces to analyze the rural land-use structure and its change in Denmark. The authors found that public regulation together with economics explains most of the changes in rural areas near cities.

Widely used, especially in Europe, is the DPSIR (Drivers-Pressures-State-Impact-Responses) concept, described on the webpage of the European Environ- mental Agency (EEA) as 'The causal framework for describing the interactions between society and the environment adopted by the European Environment Agency: driving forces, pressures, states, impacts, responses (extension of the PSR model developed by OECD)' (http://glossary.eea.eu.int/EEAGlossary/D/ DPSIR). Clearly, the DPSIR concept is not restricted to landscape change, as it includes all spheres of the environment. Since responses are included, their impact can be assessed. This is especially valuable for the evaluation of planning processes.

Regarding responses as essential part of the concept stresses the temporal aspect of system studies. Unquestionably, all elements of the system under study have a historical dimension: Not only landscapes are subjects of change, but so are actors and driving forces. Specific periods for the respective relevant group of actors (Bürgi 1999) or driving forces (Bürgi and Schuler 2003) must be defined. Selecting the appropriate periods is challenging, however. The periods should reflect major changes in the system under study, be it changes in the landscape (e.g., construction of a highway connecting a region to a city centre), or changes on the level of potential driving forces or actors (e.g., a new legislation or the rise of a new group of actors). For example, based on distinct combinations of economical, ecological, politi- 
cal, and managerial driving forces three periods were recognized in an analysis of the artificial tree regeneration practices in Swiss forests during the $19^{\text {th }}$ and $20^{\text {th }}$ century (Bürgi and Schuler 2003).

The relations between the elements, actors, and driving forces must be established and tested in the course of the analysis. Whereas statistical approaches are useful to detect correlations, they do not allow detecting causal relationships. The identification of causal relationships, however, is a prerequisite for modelling land-use and land-cover changes and for predictive studies (e.g., Serneels and Lambin 2001; Irwin and Geogheagan 2001; Verburg et al. 2002; Veldkamp and Lambin 2001; Agarwal et al. 2002).

After this short summary of the state of the art we propose seven approaches to tackle the challenges to landscape-change studies.

\section{New directions}

\section{Landscape change across borders and along transects}

Comparative studies across administrative borders or along transects are promising for studying landscape changes relating to specific driving forces. Studies across boundaries between neighbouring administrative units are especially useful for studying the effects of regulations, subsidies, and political systems. In a current project we analyze $4-8 \quad 0.25-\mathrm{km}^{2}$ plots each in five towns of the Limmat-Valley near Zurich (Figure 2). Two towns are located in the Canton Aargau, three in the Canton Zurich. The five towns were selected because their natural environment is comparable. The plots within the towns were selected randomly. In order to reduce variability among plots and towns, plots with $>50 \%$ woodland cover were excluded and for all towns the plots covering the historical centre of each town was included. We compare historical maps of the plots from the years 1930, 1956, 1976 and 2000 to determine major changes and persistence in landscape elements (woods, creeks, orchards, buildings, roads, etc.). We then analyse the relevant laws, zoning documents and political processes by archival research and interviews to determine the chain of actions which lead to the observed landscape changes and persistency. The 'story' of each landscape change and persistency will be analyzed to identify the primary and secondary driving forces, the relevant levels of hierarchies and the main actors. Since the plots are located in different cantons and municipalities, but in a comparable natural setting, we expect to uncover specifically the driving forces related to administrative units.

In another project we study landscape change along a transect from alpine to lowland areas in the St. Gallen-Alpstein region, located in north-eastern Switzerland (Figure 3). Using a similar procedure as described above, we focus on landscape change and its driving forces in three different types of communities occurring along the transect, which are predominantly urban/periurban, rural, and tourist destinations. This approach enables us in the first place to test hypotheses about the impact of specific driving forces, which change along the transect, i.e., topography, distance to centres of economic life, and accessibility.

\section{Landscape change and persistence}

In many parts of the world, landscapes are being transformed at an unprecedented high rate. In these regions, land management often attempts to reduce the rate of landscape change and to direct it in more desirable directions. Therefore, information about impeding and stabilizing factors is crucial. Clearly, studying landscape persistence, limiting factors, and constraints to change deserves the same attention as analyzing landscape change. The existence of persistence does not imply that driving forces are absent. Specifically, if appropriate driving forces such as regulations and subsidies, counter the forces of change, landscapes can exhibit temporal stability, i.e., persistence.

\section{Inherently dynamic landscapes}

Driving forces affect landscape elements and land uses which results in landscape change. However, landscapes are inherently dynamic and they can change even without being subject to extrinsic driving forces. The most obvious example of inherent dynamics is the natural succession where pioneer vegetation evolves over time to shrubland and subsequently into forest vegetation. Vegetation science often focuses on changes due to inherent dynamics of the system under study, such as succession, without considering the effects of extrinsic driving forces. In contrast, landscape history often focuses on the effects of extrinsic driving forces on landscapes and neglects the importance of inherent developments of 


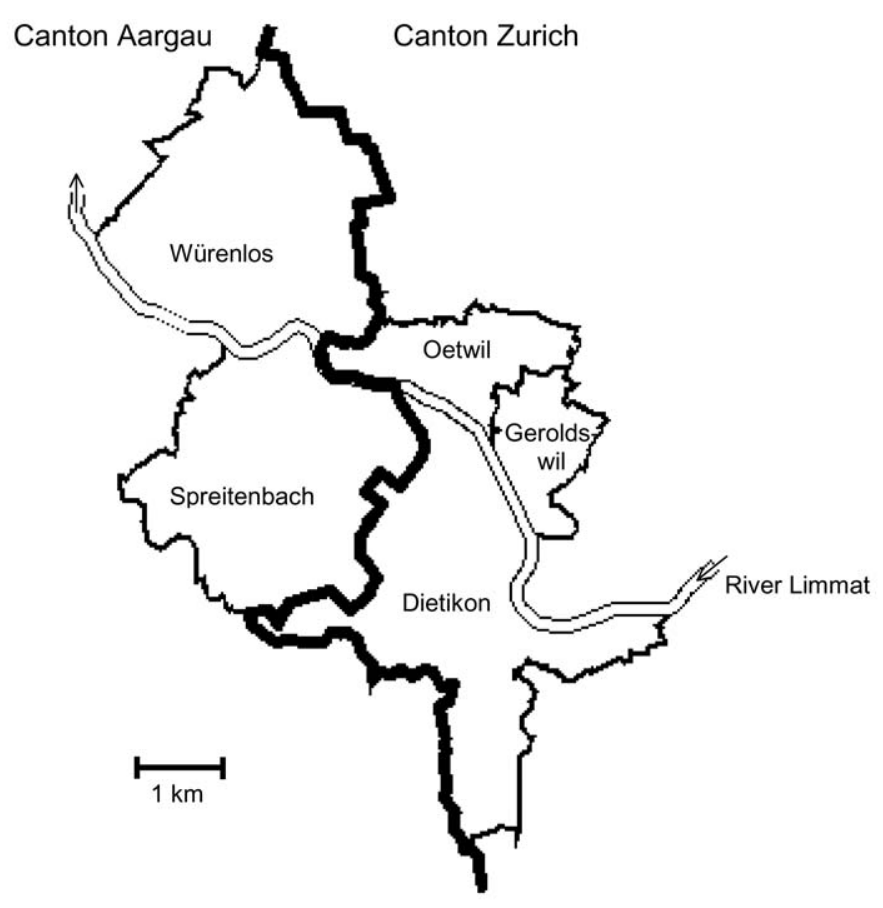

\begin{tabular}{|c|c|c|c|c|}
\hline \multicolumn{5}{|c|}{ Limmat Valley } \\
\hline \multicolumn{2}{|c|}{ Canton Aargau } & \multicolumn{3}{|c|}{ Canton Zurich } \\
\hline \multicolumn{2}{|c|}{$\begin{array}{ll}- & \text { laws and regulations } \\
- & \text { political processes } \\
- & \text { subsides and incentives }\end{array}$} & \multicolumn{3}{|c|}{$\begin{array}{ll}\text { - } & \text { laws and regulations } \\
\text { - } & \text { political processes } \\
\text { - } & \text { subsides and incentives }\end{array}$} \\
\hline Spreitenbach & Würenlos & Dietikon & Geroldswil & Oetwil \\
\hline $\begin{array}{l}\text { - zoning } \\
\text { - political } \\
\text { processes }\end{array}$ & $\begin{array}{l}\text { - zoning } \\
\text { - political } \\
\text { processes }\end{array}$ & $\begin{array}{l}\text { - zoning } \\
\text { - political } \\
\text { processes }\end{array}$ & $\begin{array}{l}\text { - zoning } \\
\text { - political } \\
\text { processes }\end{array}$ & $\begin{array}{l}\text { - } \text { zoning } \\
\text { - } \text { political } \\
\text { processes }\end{array}$ \\
\hline
\end{tabular}

Figure 2. Studying landscape change across borders enables one to analyse the impact of driving forces related to neighbouring administrative units. GIS Data: BFS GEOSTAT / Bundesamt für Landestopographie.

the system. Bridging this fundamental gap between vegetation science and landscape history could stimulate both approaches (see for example Wilson and King 1995; Foster, Motzkin and Slater 1998).

\section{Rates of change}

When landscapes change, humans, flora, and fauna adapt. The more time they are given for this process and the smoother the change is, the more likely they can cope well with the change. Thus, it is important to find out how fast the landscape has changed, i.e., to study the rate of change (Antrop 2000). If landscape change is analysed with a high temporal resolution, different rates of change and temporal trajectories can be distinguished (Figure 4), such as (a) constantly slow and (b) constantly rapid change, (c) accelerating change and (d) decelerating change, (e) isolated rapid change in the distant past, and (f) isolated rapid change in the near past.

Flora and fauna have their specific limitation to adapt to changing landscapes, given by habitat requirements and migration potential. The way how humans cope with landscape changes is best studied with appropriate methods from social sciences. Slow landscape changes for example might only get 


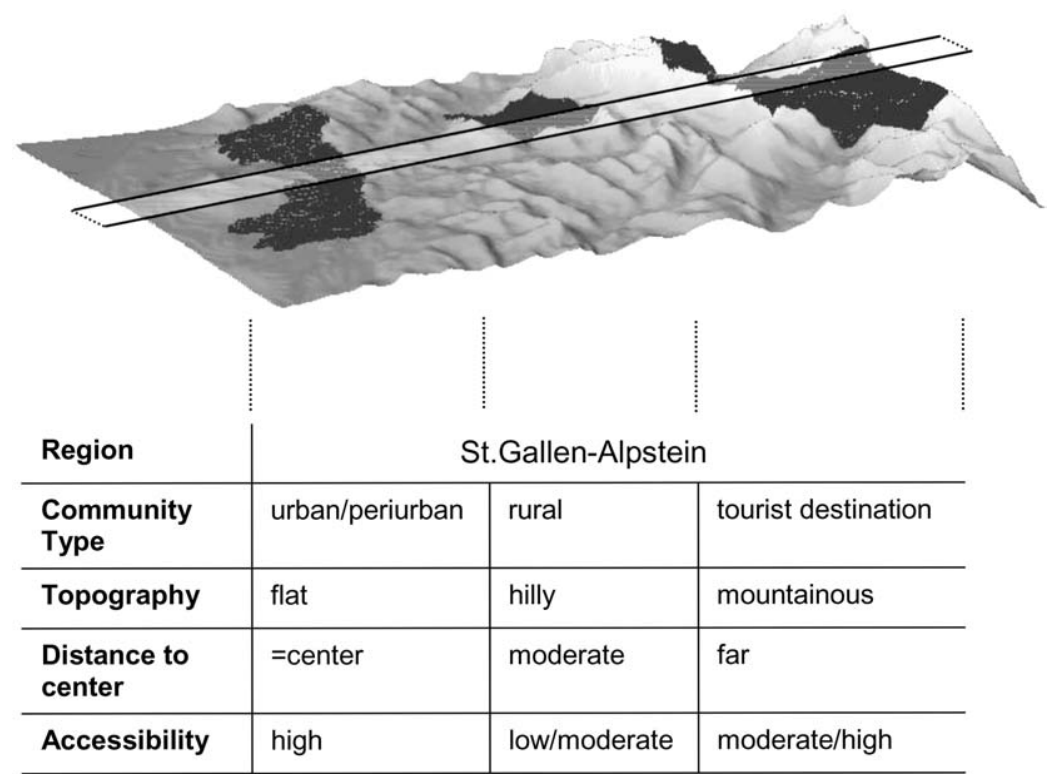

Figure 3. Studying landscape change along a transect provides insight into driving forces related to factors such as topography, distance from the centre and accessibility. GIS Data: BFS GEOSTAT / Bundesamt für Landestopographie.

(a)
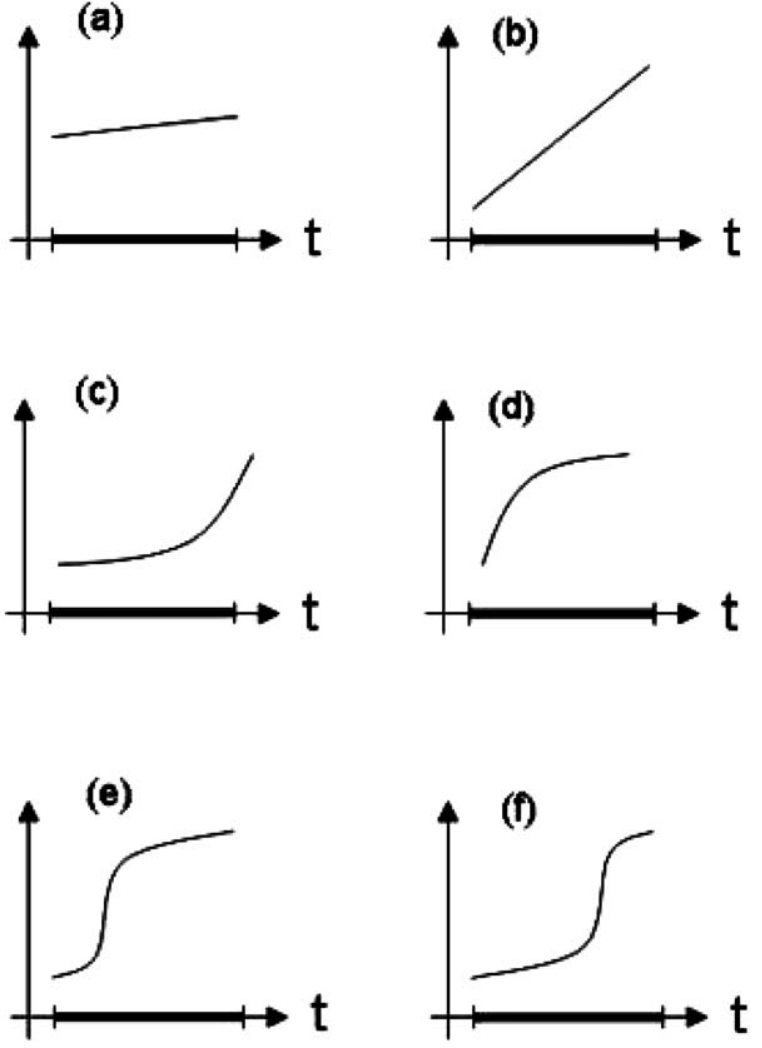

Figure 4. Rates of change. The x-coordinate shows time, the y-coordinate the investigated landscape structure. For the description of the different rates of change see text. noticed by the sporadic visitor but not by the local population. Fast, abrupt changes might result in a loss of sense of place and a decline in people's identification with the landscape.

\section{Attractors of landscape change}

If we consider a landscape exposed to a field of driving forces, we realize that not every place is equally likely to change. Some places change much more rapidly than others, since the potential for change differs from place to place. In order to understand how driving forces actually alter the landscape we therefore introduce the concept of 'attractors' of change. In general terms, an attractor of change is a site characteristic which attracts a driving force likely to induce change. A classic attractor is, for example, a highway exit. It attracts development, such as industry, housing, and new road construction. Two groups of attractors can be distinguished: site conditions and adjacency or neighbourhood relationships. The analysis of potential attractors of landscape change also provides insight into causalities of landscape changes.

\section{Precursors of landscape change}

If general patterns of landscape change exist, an extrapolation in time and place would be possible and we might be able to predict future developments. If 
we limit our prediction to specific cause and effect relationships, the term "precursor of landscape change' is appropriate. Some precursors of landscape change are visible in the landscape. For example, improvement of accessibility (e.g., Fröhlich and Axhausen 2002) is a major trigger of landscape changes by increasing export options for agriculture and industry. Thus, the construction of roads can be a precursor of landscape change. Other precursors of landscape change are not visible in the landscape: The land price can serve as a precursor for the construction of new houses, changes in agricultural subsidies can cause foreseeable changes in land use and land cover, and technical innovations can change the range of soils which can be cultivated.

Looking for precursors of landscape change based on specific cause and effect relationships might be a first step towards prediction of limited aspects of landscape change. Precursors might be especially powerful in conjunction with the scenario approach. For example, Steinitz et al. (1996, 2003) take population forecasts as a precursor in a range of scenarios of land-use change.

\section{Correlation and causality}

In all studies of land-use change, it is pivotal to distinguish between correlation and causality. Even though the aim is to increase knowledge about causalities, one is often limited to study correlations. To reach a more mechanistic understanding of landscape change, hypothesized causalities between driving forces and landscape changes can be tested with independent data. In a study on land-cover changes along the Wisconsin River, USA, major processes of land-use change were defined (e.g., farm abandonment) to explain the detected land-cover transition (e.g., shift from agricultural land to forest) (Bürgi and Turner 2002). Then, hypotheses were formulated regarding the conditions which would make the defined processes a plausible cause for the observed landcover changes. Independent data for soil characteristics, population density, and farm economic status were used to test the hypothesized causalities.

Generally, studying cause and effect relation requires an integrative approach, in which quantitative data is used together with qualitative information and narrative elements. For example, testing hypothesized impacts of driving forces can be improved by incorporating circumstantial evidence and inferential reasoning (Bürgi and Russell 2001). Sometimes, a narrative explanation based on circumstantial evidence and inferential reasoning can result in a sufficiently well grounded explanation of how driving forces caused landscape changes. A good story about the driving forces of landscape change is more than just a meagre alternative to quantification, but might well be appropriate as well as sufficient (e.g., Bicík, Jelecek and Štepanek 2001).

\section{Conclusions and Outlook}

\section{New directions put into perspective}

How do the new approaches relate to the challenges identified earlier in this paper? Most of the new approaches aim at improving our ability to study processes and not merely spatial patterns (challenge a), i.e., by testing hypothesized causalities, by taking into account the inherent dynamic of a landscape, and by studying landscape persistence, transformation rates, and attractors of landscape change.

One of the main motivations for studying the driving forces of landscape change is to find general patterns of landscape change, valid beyond the specific situation under study. The existence of general patterns of landscape change is also a prerequisite for finding precursors of landscape change and for the extrapolation in time and space (challenge b). The search for these general patterns might benefit greatly from the reconstruction of rates of change and the investigation of the appending accelerating and impeding forces. The range and the limits for extrapolating the general patterns in time and space can be determined by studying landscape change across borders and along transects.

Meeting the challenge to link data with different qualities (challenge c) will always be inherent to studies of landscape change. The concept of driving forces helps to conceptualize some of the core problems of data comparability in an interdisciplinary approach, as for an advanced understanding of driving forces the whole system has to be studied over several scales. Thus, chances are good that social and natural phenomenon will be studied at partly comparable scales. Some obstacles remain: Whereas natural scientists will have to question their maxim of spatial explicitness (as the exact spatial reference of a driving force is not always determinable), social scientists will have to reflect on the spatial dimension of the investigated force (as spatial coherences can be decisive 


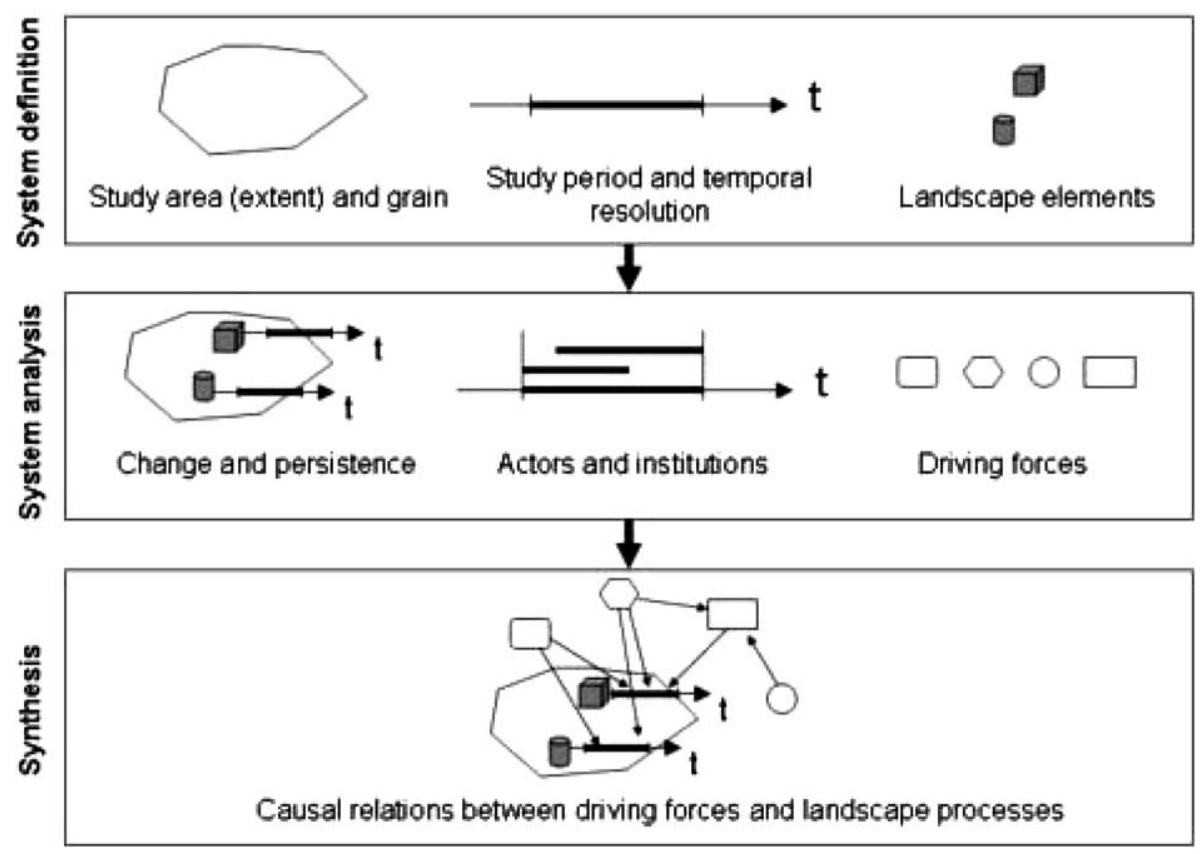

Figure 5. Standard procedure to study the driving forces of landscape change.

for the system). To define and evaluate a system of driving forces, it is crucial to find ways to combine qualitative and quantitative data.

None of the approaches and directions presented in this paper directly addresses the challenge to analyse culture as a driving force of landscape change (challenge d). However, we consider the study of driving forces as a means to foster the integration of culture and cultural change in landscape studies. The fact that we included culture as a core dimension in our framework for the study of driving forces of landscape change stresses the need to consider cultural aspects. Proctor (1998) promotes to conceive culture not as a noun but as an adjective, since cultural processes are implicated in all relevant human practices. In his understanding, culture can be seen as a means of making sense of reality. With these thoughts, we as ecologists venture out in unsafe interdisciplinary territory (e.g., Naveh 2001). The motivation to do so derives from our conviction that culture leaves a deep imprint on (cultural!) landscapes throughout the world (Nassauer 1995, 1997). A distinction between different spheres and topics where culture becomes relevant in the interaction between societies and their environment, as proposed by Nassauer (1995), facilitates the integration of culture in studies of landscape change. Comparative studies of landscape change across borders and along transects, are another approach to investigate cultural impacts on landscapes.

A standard procedure to study the driving forces of landscape change

Based on the established methods described and the new directions presented we propose a systematic procedure for studies of driving forces of landscape change. Rooted in general system theory, the procedure includes three major steps, i.e., system definition, system analysis, and system synthesis (Figure 5). A similar system-based, three-step framework has been proposed for ecological risk assessment (Sergeant 2002).

(a) System definition: Given the complexity of landscapes and landscape related processes, a clear concept regarding the aim of the study is especially vital and should be reflected in the system definition which includes defining the study area (extent) and the grain of the study, the study period and the temporal resolution, and the landscape elements of interest (Figure 5). Depending on the question, a series of study areas along a transect or across borders might be appropriate. Regarding the study period, it might make sense to choose a temporally nested approach, where certain aspects are analysed further back than others (e.g., Silbernagel et al. 1997). If one splits up 
the study period into several shorter periods, then the boundaries of the periods have to be based, as described above, on a first rough hypothesis about the main driving forces of landscape change. While defining the system under study, data availability and quality has to be considered, bearing in mind that retrospective studies are often limited by the characteristics of historical sources.

(b) System analysis: The system analysis focuses on three subsystems, i.e., the change and persistency of physical landscape elements, the actors and institutions, and the driving forces. First, change and persistency over time are determined. If several timeslices or even continuous data are included, time-lines can be established and rates of change can be studied (Figure 4). Before starting to collect data about potential driving forces, the system has to be defined in its organizational scale (Figure 1). The relevant actors and institutions are selected based on their demands, interests, and potential impacts on the landscape under study. They can be located within or outside the spatial boundaries of the system. As the relevant institutions might have changed over time, every institution has to be characterized by its period of influence.

Based on general information about the study area and the major landscape changes, the potential driving forces from the five major groups of driving forces (socioeconomic, political, technological, natural, and cultural) are named. Most landscapes are affected by driving forces from all five groups. Often, however, it is appropriate to limit a study to a subset of driving forces which are thought to be most important for understanding the landscape changes of interest. Clearly, it is important to give a rational why a study is limited to a specific set of driving forces.

(c) System synthesis: In the final synthesis, the actors, institutions, and driving forces are linked in causal relationships and their impact on the landscape elements under study is determined. The system synthesis is a challenging but crucial part in studies of driving forces. This final step stresses the fact that a landscape is always more than the sum of its elements; it is a whole (Naveh and Lieberman 1994).

\section{Outlook}

Studies of landscape change - especially studies about the change of spatial patterns - have a long tradition in landscape ecology. For a more systematic understanding of landscape change we promote to study the driving forces of change based on the new approaches and the procedure described above (Figure 5). Scientists working on this topic clearly need to be interested in interdisciplinary and integrative work to fully grasp the complexity of the system under study. Our efforts to study landscape changes in a more analytical and systematic manner are expected to improving the acceptance of interdisciplinary landscape studies in academia. As, because of its emphasis on people and their environment, landscape ecology has many management and planning applications (Hersperger 1995), we expect that the study of drivers of landscape change could greatly improve the current contribution of landscape ecology towards solving real world problems.

\section{Acknowledgements}

We thank Felix Kienast for helpful discussions and commentaries on this manuscript. The comments of two anonymous helped to improve the manuscript. This paper is a contribution to the WSL-Research focus 'Land Resources Management in Peri-Urban Environments' (www.wsl.ch/programme/periurban).

\section{References}

Adams W.M. 1990. Green development. Routledge, London, UK. Agarwal C., Green G.M., Grove J.M., Evans T.P. and Schweik C.M. 2002. A review and assessment of land-use change models: dynamics of space, time and human choice. USDA Forest Service, Gen. Tech. Rep. NE-297.

Allen T.F.H. and Starr T.B. 1982. Hierarchy: Perspectives for ecological complexity. University of Chicago Press, Chicago, Illinois, USA.

Antrop M. 1998. Landscape change: plan or chaos. Landscape and Urban Planning 41: 155-161.

Antrop M. 2000. Changing patterns in the urbanized countryside of Western Europe. Landscape Ecology 15: 257-270.

Baker W.L. 1989. A review of models of landscape change. Landscape Ecology 2: 111-133.

Baur B. 2002. Preconditions and driving factors in (non-)developing financial instruments in Swiss forest policy - a tentative politico-economic analysis. In: Ottisch A., Tikkanen I. and Riera P. (eds), Financial instruments of forest policy. EFI Proceedings No. 42.

Berger J. 1987. Guidelines for landscape synthesis: Some directions - old and new. Landscape and Urban Planning 14: 295-311.

Bicík I., Jelecek L. and Štepanek V. 2001. Land-use changes and their social driving forces in Czechia in the 19th and 20th centuries. Land Use Policy 18: 65-73. 
Blaikie P. 1985. The political economy of soil erosion. Longman, London, UK.

Blaikie P. and Brookfield H. 1987. Land degradation and society. Methuen, London, UK.

Brandt J., Primdahl J. and Reenberg A. 1999. Rural land-use and dynamic forces - analysis of 'driving forces' in space and time. In: Krönert R., Baudry J., Bowler I.R. and Reenberg A. (eds), Land-use changes and their environmental impact in rural areas in Europe. UNESCO, Paris, France, pp. 81-102.

Bürgi M. 1999. A case study of forest change in the Swiss lowlands. Landscape Ecology 14: 567-575.

Bürgi M. and Russel E.W.B. 2001. Integrative methods to study landscape changes. Land Use Policy 18: 9-16.

Bürgi M. and Schuler A. 2003. Driving forces of forest management - an analysis of regeneration practices in the forests of the Swiss Central Plateau during the 19th and 20th century. Forest Ecology and Management 176: 173-183.

Bürgi M. and Turner M.G. 2002. Factors and processes shaping land cover and land cover changes along the Wisconsin River. Ecosystems 5: 184-201.

Christensen N.L. 1989. Landscape history and ecological change. Journal of Forest History 33: 116-125.

Cronon W. 2000. Resisting monoliths and tabulae rasae. Ecological Applications 10: 673-675.

Dale V.H., Brown S., Haeuber R.A., Hobbs N.T., Huntly N., Naiman R.J., Riebsame W.E., Turner M.G. and Valone T.J. 2000. ESA Report: Ecological principles and guidelines for managing the use of land. Ecological Application. 10: 639-670.

Dale V.H., O’Neill R.V., Pedlowski M. and Southworth F. 1993. Causes and effects of land-use change in Central Rondonia, Brazil. Photogrammetric Engineering and Remote Sensing 59: 9971005.

Egan D. and Howell E.A. 2001. The historical ecology handbook. Island Press, Washington DC, USA.

Forman R.T.T. and Godron M. 1986. Landscape ecology. John Wiley and Sons, New York, New York, USA.

Foster D.R., Motzkin G. and Slater B. 1998. Land-use history as long-term broad-scale disturbance: Regional forest dynamics in Central New England. Ecosystems 1: 96-119.

Fröhlich P. and Axhausen K.W. 2002. Development of car-based accessibility in Switzerland from 1950 through 2000. Proceedings $2^{\text {nd }}$ STRC Conference, Ascona, March 20-22 (http://www.strc.ch/2002.html).

Hersperger A.M. 1994. Landscape ecology and its potential application to planning. Journal of Planning Literature 9: 15-29.

Hersperger A.M. 1995. Ökologische Planung und Landschaftsökologie. DISP Oktober: 10-19.

Hobbs R. 1997. Future landscapes and the future of landscape ecology. Landscape and Urban Planning 37: 1-9.

Irwin E.G. and Geoghegan J. 2001. Theory, data, methods: developing spatially explicit economic models of land use change. Agriculture, Ecoystems \& Environment 85: 7-24.

Kates R.W., Turner B.L. and Clark W.C. 1990. The great transformation. In: Turner B.L., Clark W.C., Kates R.W., Richards J.F., Mathews J.T. and Meyer W.B. (eds), The earth as transformed by human action. Cambridge University Press, Cambridge, UK, pp. 1-17.

Kienast F., Bürgi M. and Wildi O. in press. Landscape research in Switzerland: exploring space and place of a multi-ethnic society. BELGEO.
Lambin E.F., Turner B.L., Geist H.J., Agbola S.B., Angelsen A., Bruce J.W., Coomes O.T., Dirzo R., Fischer G., Folke C., George P.S., Homewood K., Imbernon J., Leemans R., Li X., Moran E.F., Mortimore M., Ramakrishnan P.S., Richards J.F., Skanes H., Steffen W., Stone G.D., Svedin U., Veldkamp T.A., Vogel C. and Xu J. 2001. The causes of land-use and land-cover change: moving beyond the myths. Global Environmental Change 11: 261-269.

Leser H. 1991. Landschaftsökologie: Ansatz, Modelle, Methodik, Anwendungen. Ulmer, Stuttgart, Germany.

Magnuson J.J. 1990. Long-term ecological research and the invisible present. BioScience 40: 495-501.

Marcucci D.J. 2000. Landscape history as a planning tool. Landscape and Urban Planning 49: 67-81.

McDonnell M.J. and Pickett S.T.A. 1993. Humans as components of ecosystems - the ecology of subtle human effects and populated areas. Springer, New York, New York, USA.

Meyer W.B. and Turner B.L. 1994. Changes in land use and land cover: a global perspective. University Press, Cambridge, UK.

Nassauer J.I. 1995. Culture and changing landscape structure. Landscape Ecology 10: 229-237.

Nassauer J.I. 1997. Placing nature. Culture and landscape ecology. Island Press, Washington DC, USA.

Naveh Z. 2001. Ten major premises for a holistic conception of multifunctional landscapes. Landscape and Urban Planning 57: 269-284.

Naveh Z. and Lieberman A.S. 1994. Landscape ecology: theory and application. Springer, New York, USA.

Proctor J.D. 1998. The meaning of global environmental change: retheorizing culture in human dimensions research. Global Environmental Change 8: 227-248.

Rockwell R.C. 1994. Culture and cultural change. In: Meyer W.B. and Turner B.L. (eds), Changes in land use and land cover: a global perspective. Cambridge University Press, Cambirdge, UK, pp. 357-382.

Russell E.W.B. 1994. The use of theory in land management decisions - the New-Jersey pine barrens. Biological Conservation 68: 263-268.

Russell E.W.B. 1997. People and the land through time: linking ecology and history. Yale University Press, New Haven, USA.

Sergeant A. 2002. Ecological risk assessment: history and fundamentals. In: Paustenbach D.J. (ed.), Human and ecological risk assessment. John Wiley and Sons, New York, New York, USA, pp. $369-442$.

Serneels S. and Lambin E.F. 2001. Proximate causes of land-use change in Narok District, Kenya: a spatial statistical model. Agriculture, Ecoystems \& Environment 85: 65-81.

Silbernagel J., Martin S.R., Gale M.R. and Chen J. 1997. Prehistoric, historic, and present settlement patterns related to ecological hierarchy in the Eastern Upper Peninsula of Michigan, USA. Landscape Ecology 12: 223-240.

Steinitz C., Arias H., Basset S., Flaxman M., Goode T., Maddock T., Mouat D., Peiser R. and Shaerer A. 2003. Alternative futures for changing landscapes: The upper San Pedro River Basin in Arizona and Sonora. Island Press, Washington DC, USA.

Steinitz C., Binford M., Cote P., Edwards T., Ervin S., Forman R.T.T., Johnson C., Kiester R., Mouat D., Olson D., Shearer A., Toth R. and Wills R. 1996. Biodiversity and landscape planning: alternative futures for the region of Camp Pendleton, California. Harvard University, Graduate School of Design, Cambridge, Massachusetts, USA. 
Tress B., Tress G., Décamps H. and d'Hauteserre A.-M. 2001. Bridging human and natural sciences in landscape research. Landscape and Urban Planning 57: 137-141.

Turner B.L., Clark W.C., Kates R.W., Richards J.F., Mathews J.T. and Meyer W.B. (eds), 1990. The earth as transformed by human action: Global and regional changes in the biosphere over the past 300 years. Cambridge University Press, Cambridge, UK.

Urban D.L., ONeill R.V. and Shugart H.H.J. 1987. Landscape ecology: a hierarchical perspective can help scientists understand spatial patterns. BioScience 37: 119-127.

Veldkamp A. and Lambin E.F. 2001. Predicting land-use change. Agriculture, Ecoystems \& Environment 85: 1-6.

Verburg P.H., Soepboer W., Veldkamp A., Limpiada R., Espaldon V. and Mastura S.S.A. 2002. Modeling the spatial dynamics of regional land use: The CLUE-S model. Environmental Management 30: 391-405.

Vogt K.A., Grove M., Asbjornsen H., Maxwell K.B., Vogt D.J., Sigurdardotter R., Larson B.C., Schibli L. and Dove M. 2002. Linking ecological and social scales for natural resource management. In: Lui J. and Taylor W.W. (eds), Integrating landscape ecology into natural resource management, University Press, Cambridge, UK, pp. 143-175.
Whitney G.G. 1994. From coastal wilderness to fruited plain. A history of environmental change in temperate North America from 1500 to the present. Cambridge University Press, Cambridge, UK.

Wiens J.A. 1995. Landscape mosaics and ecological theory. In: Hansson L., Fahrig L. and Merriam G. (eds), Mosaic landscapes and ecological processes. Chapman and Hall, London, UK, pp. $1-26$.

Wilson J.B. and King W.M.G. 1995. Human-mediated vegetation switches as processes in landscape ecology. Landscape Ecology 10: 191-196.

Wirth E. 1969. Zum Problem einer allgemeinen Kulturgeographie: Raummodelle - kulturgeographische Kräftelehre - raumrelevante Prozesse - Kategorien. Die Erde 2-4: 155-193.

Wood R. and Handley J. 2001. Landscape dynamics and the management of change. Landscape Research 26: 45-54.

Wu J. and Hobbs R. 2002. Key issues and research priorities in landscape ecology: an idiosyncratic synthesis. Landscape Ecology 17: $355-365$. 